\title{
Annealing Effects on the Crystallinity of Carbon Fiber-Reinforced Polyetheretherketone and Polyohenylene Laminate Composites Manufactured by Laser Automatic Tape Placement
}

\author{
Svetlana RISTESKA ${ }^{1}$ *, Anka TRAJKOVSKA PETKOSKA ${ }^{2}$, Samoil SAMAK ${ }^{3}$, \\ Marian DRIENOVSKY ${ }^{4}$
}

\author{
${ }^{1}$ Institute for advance and composite and robotics, Krusevki pat, bb 7500 Prilep, Macedonia \\ ${ }^{2}$ Faculty of Technology and Technical Sciences-Veles, University "St. Kliment Ohridski" - Bitola, Macedonia \\ ${ }^{3}$ Mikrosam A.D., Krusevki pat, bb 7500 Prilep, Macedonia \\ ${ }^{4}$ Faculty of Materials Science and Technology in Trnava, Slovak University of Technology, Jana Bottu 25, 91724 Trnava, \\ Slovakia
}

crossref http://dx.doi.org/10.5755/j01.ms.26.3.21489

Received 27 September 2018; accepted 01 March 2019

\begin{abstract}
In situ consolidation of thermoplastic composites by Automated Tape Placement (ATP) is challenging. High quality ATP grade pre-preg material and tape head equipped with an efficient heat sources like lasers offer an opportunity towards high deposition rates and improved mechanical properties of composite materials. In this study uni-directional carbon fiber/ polyphenylene sulfide (UD tape prepreg CF/PPS), carbon fiber/polyetheretherketone (UD tape prepreg CF/PEEK) as well as blend of carbon fiber/polyetheretherketone/polyphenylene sulfide (UD tapes prepregs CF/PEEK/PPS) laminates are compared in terms of their properties after beeing processed by ATP technology. CF/PPS, CF/PEEK and blend CF/PPS/PEEK laminate specimens were processed using in-situ laser-assisted ATP (LATP) process. LATP processing parameters used in this study were chosen based on a preliminary trials; the results provide a basis for refinement of these parameters and prepreg material with an optimal and balanced set of final mechanical properties. This study showed an attempt how to manage the processing parameters for LATP process and to obtain composite materials with tailored properties. The process for production of thermoplastic plates with LATP head in general is a process that is governed by many parameters such as: laser power, angle of incidence, roller pressure and temperature, placement speed, tool temperature, then types of the roller material and the tool material. These parameters are not subject of discussing in this paper; they are kept constant, and the goal of the paper is to manage the crystallinity level within the composite thermoplastic material during annealing step at different temperatures after LATP process. Also, the void content during the production process could be controlled. More particularly, the authors showed that composites based on PPS matrix manufactured with LATP process possess higher flexural strength, with less void content compared to samples based on PEEK matrix. These samples showed also higher crystallinity after annealing step.

Keywords: thermoplasts, laser-assisted automated tape placement (LATP), degree of crystallinity, void content, flexural strength.
\end{abstract}

\section{INTRODUCTION}

Thermoplastic composites are expected to undergo substantial growth over the next $10-20$ years. The main advantages of thermoplastics compared to thermosetting composites are: rapid processing, reduced volatiles, improved reuse/recycle cycles, and in some cases reduced materials cost. These composites are attractive for application in the civil and military aerospace industry due to the high stiffness, fracture toughness, compressive strength, good impact, fatigue and chemical resistance properties. Another advantage of thermoplast composites is their ability to re-melt, which widens the possibilities in product and production process designs [1-5].

Thermoplastic tape placement is a special case of an out of autoclave process; it has high potential for aerospace industry due to its high degree of automation. Unidirectional (UD) continuous fiber reinforced tapes with high fiber content are used as semi-finished material. These tapes are usually fully impregnated and consolidated with void content of approx. from 0.07 to $3.70 \%$. Within the thermoplastic tape placement process, tapes are melted by a heat source like, laser beam, infrared light, hot gas torch, and bonded to laminates by compaction force induced by a consolidation roller. During consolidation step, the tapes are cooled down to tool temperature (tool is made of $\mathrm{Al}$ alloys) $[1,2]$.

The recent advances in automated manufacturing technology of composite materials resulted in a highly promising process called fiber placement. The advantages of fiber-placement processes can be combined with the high throughputs that can be achieved using thermoplastic prepreg tape that can be shaped and consolidated online. This is enabled due to the chemical structure of the resin that melts under the heat regime and consolidation before the cooling step. Thus online consolidation technology has some advantages such as: i) eliminates the use of an autoclave by applying heat directly at the nip-point, ii)

\footnotetext{
* Corresponding author. Tel.: ++389-70-353695; fax: ++389 (0)48 434

072. E-mail address: svetlanar@iacr.edu.mk (S. Risteska)
} 
welding the tape on the preceding layer under compaction pressure, and iii) consolidating shortly behind the nip-point where the temperature is usually lower than in the previous step. Mechanisms governing strength buildup and consolidation during thermoplastic fiber-placement processes should be well understood in order to control the processing parameters to obtain the optimum product quality [3]. Laser-assisted tape placement was studied by many authors and described in literature [4-17]. Particularly, crystallization kinetics behavior of Polyetheretherketone (PEEK) based composites exposed to high heating and cooling rates is investigated by Tierney et. al., [16]. The rapid and appreciable crystal growth occurs under ultra-high heating and cooling rates.

Welding of semicrystalline thermoplastic UD tapes with LATP (Laser-Assisted Tape-Placed) process is also analyzed in literature as well [6-10]. These studies have led researchers to measure the temperature distribution in the vicinity of the welded process zones [17-32]. The thermal history of the composite material during processing by LATP is of great benefit to understand the bond quality and the properties that control e.g., crystallinity and void content in composite materials.

For different commercially available thermoplastic tapes it is very important to identify a LATP process. The microstructure, bond strength measured by 3-point bending test (3-pbt) and degree of crystallinity of tested tapes at different temperatures are also presented. Good agreement between experimental and theoretical data was observed for examined samples.

\section{EXPERIMENTAL DETAILS}

\subsection{Materials}

The thermoplastic composite materials evaluated in this study are:

- LATP1: UD prepreg material Suprem ${ }^{\mathrm{TM}} \mathrm{T}$ with Carbon-fibre (Hexcel AS4 carbon fibre) and matrix PPS (Ticona 0214 PPS) supplied by Suprem ${ }^{\mathrm{TM}}$ (Switzerland);

- LATP2: UD prepreg material Tenax®-E TPUD PEEKHTS45 with Carbon-fibre (Tenax®-E HTS45 12K carbon fibre) and matrix PEEK (Vitrex 150 PEEK) supplied by Toho Tenax (Germany), and

- LATP3: UD blended prepreg material Tenax®-E HTS45/150PEEK + Suprem ${ }^{\mathrm{TM}}$ T $60 \%$ AS4/PPS-214 with $50 / 50 \%$.

Table 1. Description of UD prepregs (used in this study)

\begin{tabular}{|l|c|c|}
\hline Materials & $\begin{array}{c}\text { Tenax }{ }^{\circledR}-E \text { TPUD } \\
\text { HTS45/150PEEK }\end{array}$ & $\begin{array}{c}\text { Suprem } \\
\text { ASM T } 60 \%\end{array}$ \\
\hline $\begin{array}{l}\text { Prepreg areal } \\
\text { weight }\end{array}$ & $220 \mathrm{~g} / \mathrm{m}^{2}$ & $305 \mathrm{~g} / \mathrm{m}^{2}$ \\
\hline Fibre areal weight & $145 \mathrm{~g} / \mathrm{m}^{2}$ & $200 \mathrm{~g} / \mathrm{m}^{2}$ \\
\hline Matrix content & $34 \mathrm{wt} \%$ & $34 \mathrm{wt} . \%$ \\
\hline $\begin{array}{l}\text { Nominal thickness } \\
\text { Matrix glass } \\
\text { transition } \\
\text { temperature }(T \mathrm{~g})\end{array}$ & $0.14 \mathrm{~mm}$ & $0.19 \mathrm{~mm}$ \\
\hline $\begin{array}{l}\text { Matrix melting } \\
\text { temperature }(T \mathrm{~m})\end{array}$ & $143{ }^{\circ} \mathrm{C}$ & $80-90{ }^{\circ} \mathrm{C}$ \\
\hline
\end{tabular}

All examined composite materials are summarized in Table 1. The tapes with $25.4 \mathrm{~mm}$ width were selected for LATP process investigated in this work.

\subsection{LATP process (laser-assisted ATP manufacturing)}

The LATP process could be specified by a multitude of interdependent variables:

- LATP operational parameters: laser energy density, angle of incidence, roller pressure (roller consolidation force), placement speed, tape placement track overlap from layer to layer, tool temperature and roller temperature;

- LATP hardware parameters: roller material, tool material, and

- Prepreg properties: surface roughness, void content, initial crystallinity level, tape width.

A complex relationship exists between all of these variables and the resulting bond strength of composites. One of the most critical variable is the heat source and the resulting temperature distribution in the incoming tape and substrate, which strongly influences the resulting mechanical properties that could be ,measured, through final void content as well as crystallinity level (in case of semi-crystalline thermoplastics such as: PEEK and PPS).

In this study, laminates were obtained by using a laserassisted tape placement head (LATP) manufactured by Mikrosam, Macedonia. LATP head is attached to a robot arm (product by Kuka, KR 420 R3080), as it is shown in Fig. 1.

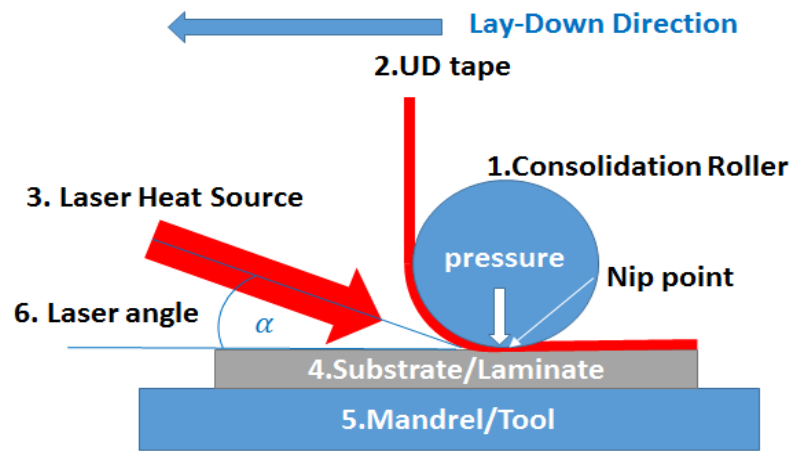

Fig. 1. A laser-assisted tape placement head (LATP): 1-a consolidation roller (outer diameter of $90 \mathrm{~mm}$ ); 2 - a tape feed, guidance, tensioning, and cutting system for UD tape; 3 - type -diode laser $3 \mathrm{~kW}$, lens - type/focal length: array 2 LL-line 2.20; array 1-LL-line 2.10, spot dimension: laser beam width $28 \mathrm{~mm}$ and laser beam height $56 \mathrm{~mm}$, focus: $250 \mathrm{~mm}$ by Laserline company; the heat source is focussed under angle $\alpha ; 4$-a substrate or laminate; 5 - mandrel (tool) and a temperature sensor (pyrometer) that is built in the laser system

Flat panels (samples) were produced using LATP head. The laser and pyrometer were set to operate in closed-loop control, i.e. the laser energy was controlled to minimize the error between the set point temperature and feedback temperature measurement from the pyrometer. All factors such as: type materials and process parameters for LATP (laser energy density, tool temperature, consolidation force, laser angle of incidence, etc.) have a big influence on the interplay as well as on the void content inside the laminate 
made by LATP $[17,18]$. In this study, the processing parameters (presented in Table 2) were chosen based on a number of trials performed by LATP - head [17].

Table 2. Laser assisted ATP (LATP) processing parameters used in the current study

\begin{tabular}{|l|c|c|c|}
\hline Materials & LATP1 & LATP2 & LATP3 \\
\hline Lay-up angle & {$[0]_{8^{*}}$} & {$[0]^{*}$} & {$[0]_{10^{*}}$} \\
\hline Lay- down speed & \multicolumn{3}{|c|}{$9 \mathrm{~m} / \mathrm{min}$} \\
\hline Target temperature & $360{ }^{\circ} \mathrm{C}$ & $420{ }^{\circ} \mathrm{C}$ & $400{ }^{\circ} \mathrm{C}$ \\
\hline Tool temperature & \multicolumn{3}{|c|}{ Unheated/no cooling } \\
\hline Roller material & \multicolumn{3}{|c|}{ Rubber } \\
\hline Tool material & \multicolumn{3}{|c|}{ Stainless steel } \\
\hline angle of incidence & \multicolumn{3}{|c|}{$22.5^{0}$} \\
\hline $\begin{array}{l}\text { Roller pressure } \\
\text { consolidation f) }\end{array}$ & \multicolumn{3}{|c|}{3.8 bar $(365.56 \mathrm{~N})$} \\
\hline *-numbers of layers & \multicolumn{3}{|}{} \\
\hline
\end{tabular}

\subsection{Characterization of LATP laminates}

\subsubsection{Optical microscopy characterization}

The preparation and procedure for preparing the micrographic specimens of polymer composite materials in general is described elsewhere [33-37]. A sample was extracted from each plate of the LATP laminates (LATP1, LATP2 and LATP3), mounted in epoxy resin, grinded and adequately polished for further examination.

The image capture and analysis were performed and they were evaluated for the void content for each of the laminates manufactured by LATP process. Segmentation of the fibres, resin and voids were performed on selected regions (10 images first method) using image analysis software Image J (NIH ) [38].

The void content of composite product is very important parametar that characterizes the quality of the produced composite part. It was used also second method to characterize the quality of the produced part and it was calculated using the experimental and theoretical density of the composite according to Eq 1 [40]:

$V_{\text {void }}=\frac{\left(\rho_{c t}-\rho_{c e}\right)}{\rho_{c t}}$

where: $V_{\text {void }}$ is void content of the composite; $\rho_{\mathrm{ct}}$ is theoretical density of the composite $\left(\mathrm{kg} / \mathrm{m}^{3}\right) ; \rho_{\text {ce }}$ is experimental density of the composite $\left(\mathrm{kg} / \mathrm{m}^{3}\right)$. As stated above, method A from ASTM-D 792 standard was used to calculate the experimental density $\rho_{\mathrm{ce}}$ of the composite [40].

\subsubsection{Mechanical tests}

A three-point bending test was performed to measure the flexural mechanical properties of the composites according to ASTM D-790. Specimens with dimensions of $50.0 \mathrm{~mm} \times 15.0 \mathrm{~mm} \times 1.5 \mathrm{~mm}$ were tested at $5 \mathrm{~mm} / \mathrm{min}$ crosshead speed and constant span at $L=16 \cdot d$ (d is thickness of the specimens). The composites produced only by LATP usually show smaller values of flexural strength and stiffness compared to composites produced by autoclave process [27].

The flexural strength, $\sigma_{\max }$ can be determined by equations 2 and 3 [41]:

$\sigma_{\max }=\frac{3}{2} \frac{\boldsymbol{F}_{\max } \boldsymbol{L}}{\boldsymbol{b d}^{2}}$
$E_{f}=\frac{1}{4} \frac{L^{3}}{b d^{3}} \frac{\Delta F}{\Delta t}$,

where: $F$ is load at a given point on the load-deflection curve in $\mathrm{N} ; b$ and $d$ are the width and thickness of samples tested in $\mathrm{mm}$, respectively; $L$ is a support span in $\mathrm{mm}, E_{\mathrm{f}}$ is the flexural modulus of elasticity given in $\mathrm{MPa}, \Delta t$ is difference in deflection between $\mathrm{t}_{1}$ and $\mathrm{t}_{2} ; \Delta F$ is difference in load; $F_{1}$ and $F_{2}$ at $t_{1}$ and $t_{2}$, respectively [41].

\subsubsection{Determination of degree of crystallinity of tested laminates}

Differential scanning calorimetry (DSC, Netzsch model STA 409CD) was used to measure samples LATP1, LATP2 and LATP3 in order to determine the degree of crystallinity of the tape after laser automatic tape placement at room temperature as well at different temperatures after annealing step.

The crystallinity of the welded tape (before and after the annealing step) was determined by heating samples from room temperature up to $600{ }^{\circ} \mathrm{C}$ with a heating rate of $10^{\circ} \mathrm{C} / \mathrm{min}$. The tests were carried out under Ar atmosphere. The degree of the crystalline $\left(\mathrm{X}_{\mathrm{c}}\right)$ is calculate with Eq. 4 [29]:

$X_{c}=\frac{\left|\Delta H_{m}\right|-\left|\Delta H_{c}\right|}{\Delta H_{f}\left(1-w_{f}\right)} \times 100 \% ;\left(1-w_{f}\right)=w_{m}$,

where: $\Delta H_{\mathrm{m}}$ and $\Delta H_{\mathrm{c}}$ are values of the melting enthalpy and the cold crystallization enthalpy, respectively $\left(\Delta H_{\mathrm{m}}\right.$ is positive and $\Delta H_{\mathrm{c}}$ is negative).

The value for $\Delta H_{\mathrm{f}}$ represents the melting enthalpy of PPS at $100 \%$ crystallinity (or PEEK with $100 \%$ crystallinity); these values are $150.4 \mathrm{~J} / \mathrm{g}$ for PPS and $130 \mathrm{~J} / \mathrm{g}$ for PEEK, respectively $[18,19]$. The matrix weight fraction $\left(\mathrm{w}_{\mathrm{m}}=1-\mathrm{w}_{\mathrm{f}}\right.$ calculated from Eq. 4 for LATP1, LATP2 and LATP3 is provided by the manufacturers and equals to 0.34 for both, the tape and the laminate (this value (0.34) is used for calculations).

\section{RESULTS AND DISCUSSION}

\subsection{Void content in laminates}

Fig. $3 \mathrm{~d}$ presents various locations within the tested composite samples, where void content were measured by optical microscopy. Void content is increased during the LATP2 process while it is reduced in the case of LATP3. This is an important observation and indicates that void rebound has occurred during the LATP process.

Void content in the composite was determined according to two methods: 10 images (first method) and 10 samples (for second method) [39, 40]. In the LATP1 sample voids are up to $2 \%$, while in the LATP2 sample, voids are noted with max value of $8.7 \%$. For LATP3 samples, the $\max$ value of void content reached to $\sim 6.3 \%$. The void content is relatively higher for LATP2 and LATP3, but still they belong within the allowed average limits for thermoplastic that usually is up to $5+/-1 \%$ ). For samples of LATP2, void content is relatively high and required further experimentation to overcome this issue in order to manufacture a composite within allowed void content and acceptable mechanical properties. Fig. 3 2D microscopy images from a cross-section of samples LATP 1-3: (i) 
sample extracted at the begining of LATP process (process has just started); (ii) sample extracted from the mid region (the process is in its middle regime); (iii) sample extracted from the region at the final stage of LATP process.

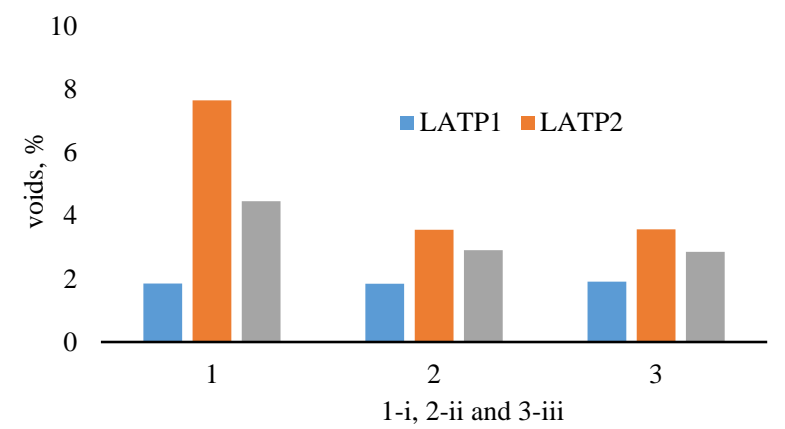

\begin{tabular}{|c|c|c|c|c|c|c|}
\hline Type & $\mathrm{i}$ & $\mathrm{i}$ & ii & iii & iii & Average \\
\hline \multirow{2}{*}{ LATP1 } & 1.90 & 1.80 & 1.80 & 1.87 & 1.87 & \multirow{2}{*}{1.87} \\
\hline & 1.78 & 1.92 & 1.89 & 2.05 & 1.86 & \\
\hline \multirow{2}{*}{ LATP2 } & 8.77 & 7.32 & 3.65 & 2.36 & 2.78 & \multirow{2}{*}{5.19} \\
\hline & 6.73 & 7.76 & 3.45 & 5.65 & 3.45 & \\
\hline \multirow{2}{*}{ LATP3 } & 6.29 & 3.22 & 2.56 & 2.23 & 0.96 & \multirow{2}{*}{3.50} \\
\hline & 5.43 & 2.87 & 3.24 & 4.23 & 3.98 & \\
\hline
\end{tabular}

Fig. 2. Calculation of average voids with optical microscopy for samples LATP1-3 in diferent regions: i, ii and iii

Void content is higher at the beginning of the LATP process (i) while it is reduced towards the mid and the end

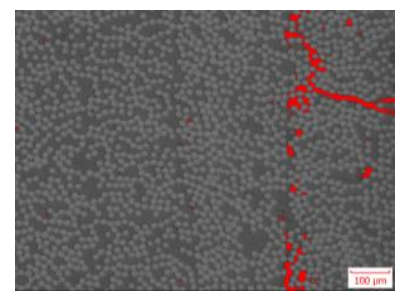

a-LATP1(i) $1.903 \%$

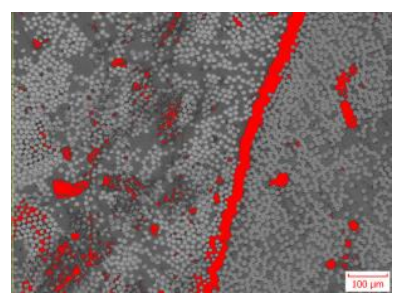

c-LATP3 (i) $6.293 \%$

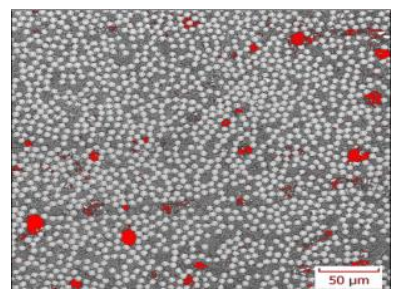

LATP1(ii-iii) $1.87 \%$

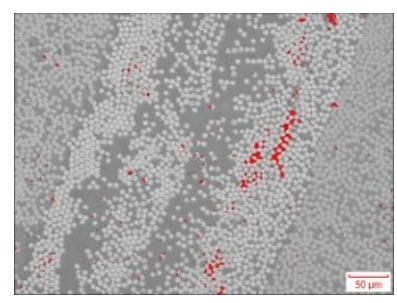

LATP3 (ii-iii) $0.961 \%$

region of the plate during LATP process (ii and iii, respectively) Fig. 2. This phenomenon is due to the high power of the laser at the begininig of the LATP process. In the following experimental tests [42] with less laser power there is a reduced void contents at the begining of the LATP process, and actually there is no big difference in the void contents all through the sample length or thickness.

\subsection{Mechanical tests of laminates}

The results of mechanical tests performed on materials manufactured by LATP process for three tested samples are presented in this section. Overall, the material produced by LATP1 performed better properties compared to reference data of the autoclaved material [27] in terms of flexural strength and flexural stiffness. These data are summarized in Table 3.

The significant knockdown in flexural strength for the LATP process (compared to autoclaved samples, Table 3 ) is thought to be a consequence of morphology and void rebound as discussed previously in section 3.1.

\subsection{Degree of crystallinity of laminates}

Fig. 4-Fig. 6 present DSC diagrams for specimens LATP1, LATP2 and LATP3, respectively. These specimens were tested at room temperature and later annealed (thermally treated) at 75,100 and $150{ }^{\circ} \mathrm{C}$ for 60 minutes, and then examined again on DSC under the same conditions.

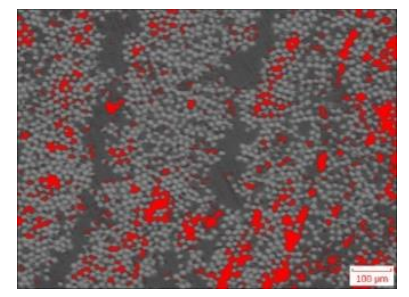

b-LATP2 (i) $8.772 \%$

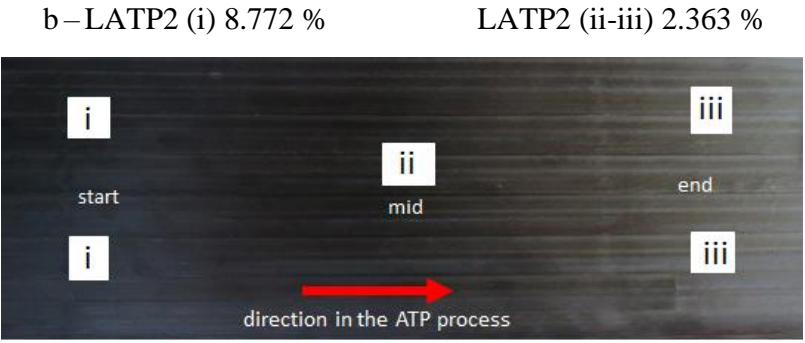

$\mathrm{d}$-locations of the samples tested for void content

Fig. 3. Images taken by optical microscopy for LATP1-3 samples and void distribution calculated with software Image (in \%). The images show max and min void content as well as distribution of phases (polymer matrx and voids) in two different spots (i and ii-iii) on cross section of LATP 1-3 samples

Table 3. Comparison of flexural properties of autoclave and ATP manufactured composites

\begin{tabular}{|c|c|c|c|c|c|}
\hline Material & $\begin{array}{c}\text { Autoclave strength, } \\
\mathrm{MPa}\end{array}$ & $\begin{array}{c}\text { ATP } \\
\text { Heat source }\end{array}$ & $\begin{array}{c}\text { Lay-down } \\
\text { speed, } \mathrm{m} / \mathrm{min}\end{array}$ & $\begin{array}{c}\text { Strength average, } \\
\text { MPa }\end{array}$ & Translation \\
\hline AS4/PEEK [37] & 1500 & Hot Gas Torch & 1.8 & $>1500$ & $100 \%$ \\
\hline CF*/PEEK [34] & 1650 & $/$ & $/$ & 1 & $/$ \\
\hline IM7/PEEK [27] & 1775 & Laser & 8 & 1207 & $70 \%$ \\
\hline AS4/PEEK LATP2 & 1650 & Laser & 9 & 1143 & $69.2 \%$ \\
\hline AS4/PPS LATP1 & 1650 & Laser & 9 & 1167 & $70.7 \%$ \\
\hline AS4/PPS/PEEK LATP3 & 1650 & Laser & 9 & \multicolumn{5}{c|}{1035} & $62 \%$ \\
\hline *Fibre type not further specified. & \multicolumn{5}{c}{} \\
\hline
\end{tabular}


The DSC traces of thee specimens LATP 1 (UD carbonPPS tape, Fig. 4) does not show the exothermal cold crystallization peak. These specimens were fully crystallized during the annealing step, a degree of crystallinity ranges from 17.1 to $27.9 \%$.

A DSC analysis also confirmed that the laminate reached maximum crystallinity with a value of $X \mathrm{c}=27.9 \%$. The carbon-PPS samples start to decompose when temperature reaches about $500{ }^{\circ} \mathrm{C}$.
Fig. 5. shows the DSC heating traces of the LATP2 (UD carbon-PEEK tape). The laminate LATP2 shows a cold crystallization peak at $173{ }^{\circ} \mathrm{C}$.

Fig 6 shows the DSC heating traces of the LATP3 (UD carbon-PEEK/PPS tape). The laminate LATP3 shows a cold crystallization peak at $173{ }^{\circ} \mathrm{C}$ and a melt peak at $342{ }^{\circ} \mathrm{C}$ for PEEK matrix as well as a melt peak at $278^{\circ} \mathrm{C}$ for PPS matrix. The DSC traces of these specimens do not show the exothermal cold crystallization peak for PPS matrix. The decomposition process starts at temperatures of $\approx 480{ }^{\circ} \mathrm{C}$.

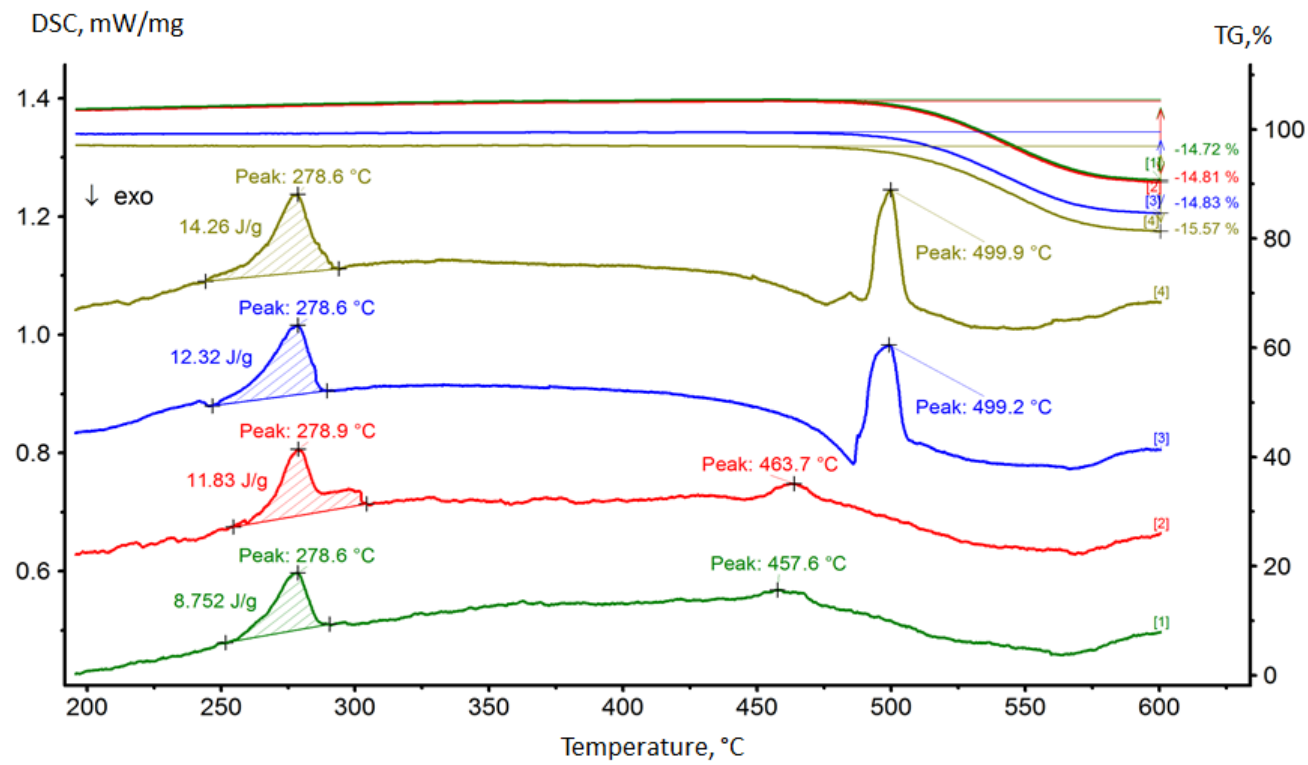

File

DSC-TG-PPS-CF RT sample LATP1

DSC-TG-PPS-CF $75^{\circ} \mathrm{C}$ - $1 \mathrm{~h}$ sample LATP1

DSC-TG-PPS-CF $100^{\circ} \mathrm{C}-1 \mathrm{~h}$ sample LATP1

DSC-TG-PPS-CF $150^{\circ} \mathrm{C}-1 \mathrm{~h}$ sample LATP1
Sample

PPS-CF-RT

PPS-CF- $75^{\circ} \mathrm{C}-1 \mathrm{~h}$

PPS-CF- $100^{\circ} \mathrm{C}-1 \mathrm{~h}$

PPS-CF- $150^{\circ} \mathrm{C}-1 \mathrm{~h}$

\begin{abstract}
Range
\end{abstract}
$27.0 / 10.0(\mathrm{~K} / \mathrm{min}) / 600.0$

$27.0 / 10.0(\mathrm{~K} / \mathrm{min}) / 600.0$

$27.0 / 10.0(\mathrm{~K} / \mathrm{min}) / 600.0$

$27.0 / 10.0(\mathrm{~K} / \mathrm{min}) / 600.0$
Atmosfere

ARGON/60/no gas/ARGON/10

ARGON/60/no gas/ARGON/10

ARGON/60/no gas/ARGON/10

ARGON/60/no gas/ARGON/10

Fig. 4. DSC/TGA curves from LATP1 of the as-received tape and the welded tapes, before and after an annealing steps

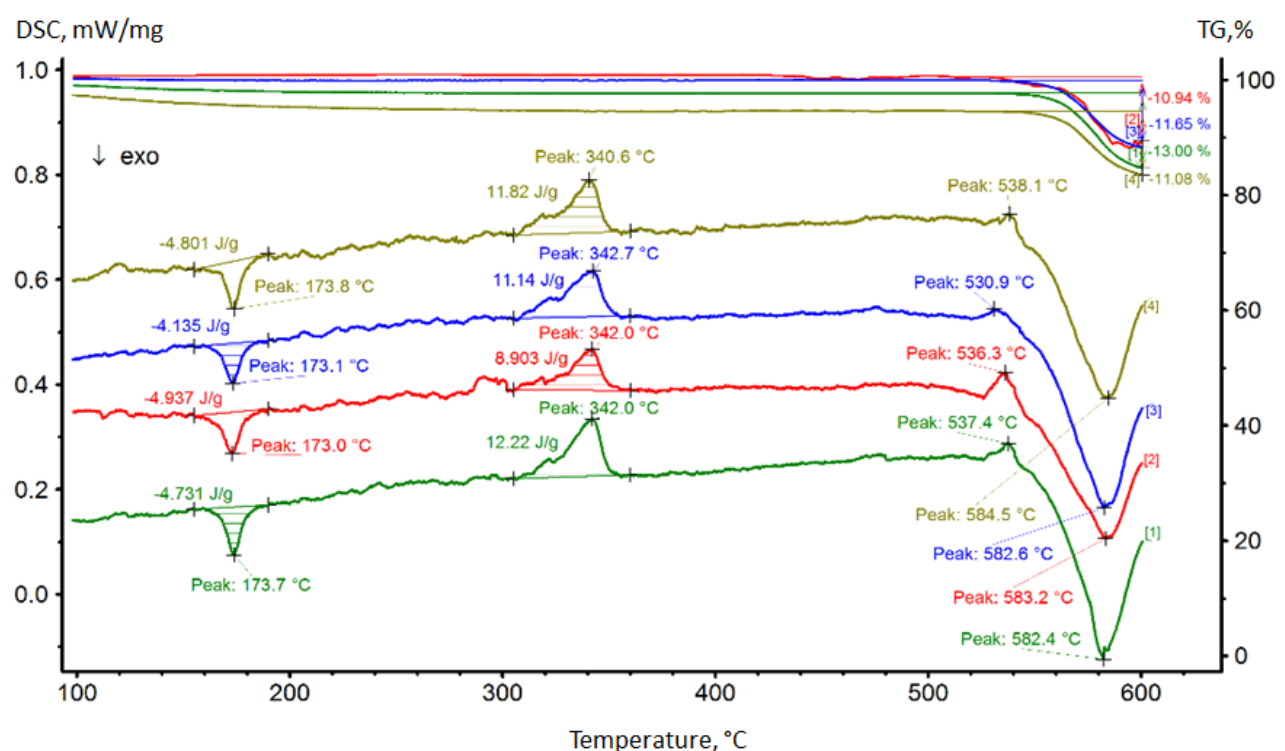

File

DSC-TG-PEEK-CF RT sample LATP2

DSC-TG-PEEK-CF $75^{\circ} \mathrm{C}-1 \mathrm{~h}$ sample LATP2

DSC-TG-PEEK-CF $100^{\circ} \mathrm{C}-1 \mathrm{~h}$ sample LATP2

DSC-TG-PEEK-CF $150^{\circ} \mathrm{C}$ - $1 \mathrm{~h}$ sample LATP2
Sample

PEEK-CF-RT

PEEK-CF- $75^{\circ} \mathrm{C}-1 \mathrm{~h}$

PEEK-CF- $100^{\circ} \mathrm{C}-1 \mathrm{~h}$

PEEK-CF- $150^{\circ} \mathrm{C}-1 \mathrm{~h}$
Range

$27.0 / 10.0(\mathrm{~K} / \mathrm{min}) / 600.0$

$27.0 / 10.0(\mathrm{~K} / \mathrm{min}) / 600.0$

$27.0 / 10.0(\mathrm{~K} / \mathrm{min}) / 600.0$

$27.0 / 10.0(\mathrm{~K} / \mathrm{min}) / 600.0$

\section{Atmosfere}

ARGON/60//ARGON/10

ARGON/60//ARGON/10

ARGON/60//ARGON/10

ARGON/60//ARGON/10

Fig. 5. DSC/TGA curves for LATP2 of the as-received tape and the welded tapes, before and after an annealing steps 


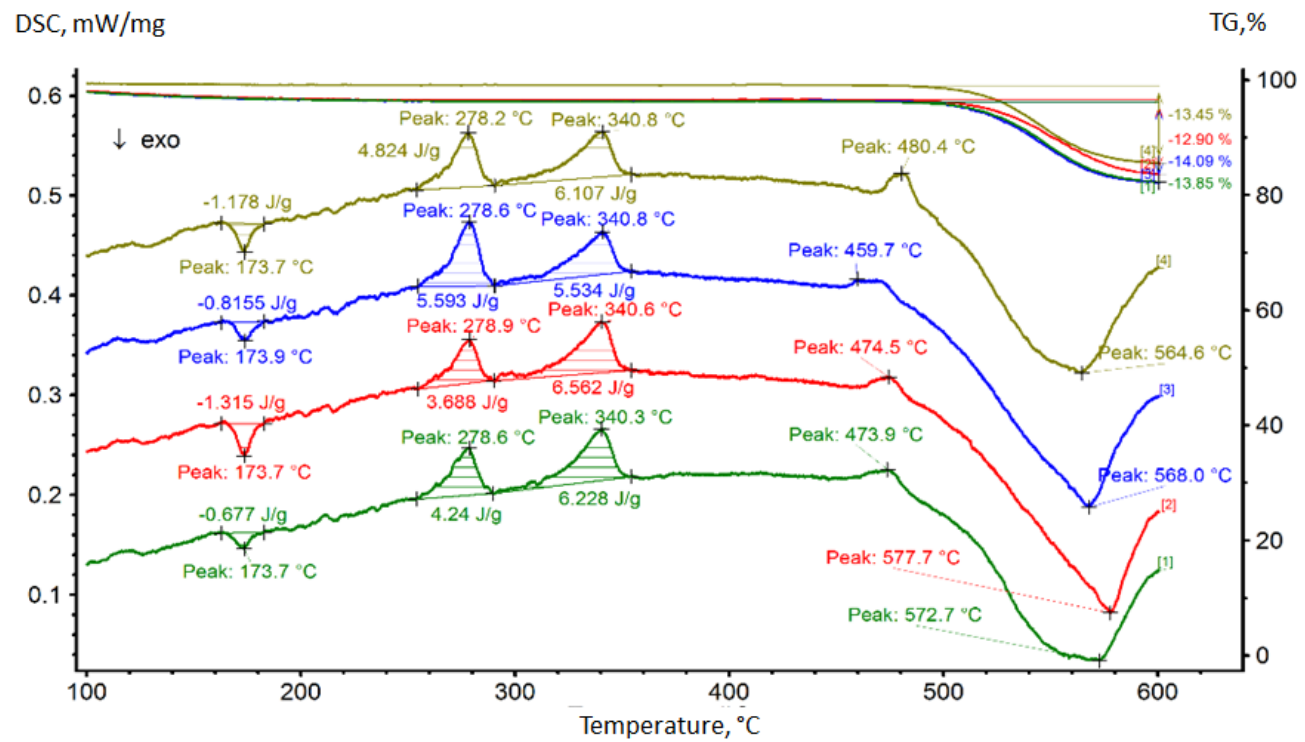

File

DSC-TG-PPS/PEEK-CF RT sample LATP3

DSC-TG-PPS/PEEK-CF $75^{\circ} \mathrm{C}-1 \mathrm{~h}$ sample LATP3

DSC-TG-PPS/PEEK-CF $100^{\circ} \mathrm{C}-1 \mathrm{~h}$ sample LATP3

DSC-TG-PPS/PEEK-CF $150^{\circ} \mathrm{C}-1 \mathrm{~h}$ sample LATP3
Sample

PPS/PEEK-CF-RT

PPS/PEEK-CF- $75^{\circ} \mathrm{C}-1 \mathrm{~h}$

PPS/PEEK-CF- $100^{\circ} \mathrm{C}-1 \mathrm{~h}$

PPS/PEEK-CF- $150^{\circ} \mathrm{C}-1 \mathrm{~h}$
Range

$27.0 / 10.0(\mathrm{~K} / \mathrm{min}) / 600.0$

$27.0 / 10.0(\mathrm{~K} / \mathrm{min}) / 600.0$

$27.0 / 10.0(\mathrm{~K} / \mathrm{min}) / 600.0$

$27.0 / 10.0(\mathrm{~K} / \mathrm{min}) / 600.0$
Atmosfere

ARGON/60/ARGO/10

ARGON/60/ARGO/10

ARGON/60/ARGO/10

ARGON/60/ARGO/10

Fig. 6. DSC/TGA curves for LATP3 of the as-received tape and the welded tapes, before and after an annealing steps

In Table 4 are presented values of degree of cristallinity (Xc) calculated from DSC diagrams for all examined specimens: LATP1, LATP2 and LATP3.

Fig. 7 presents the degree of cristalinity vs. different temperatures of anneaed composites designated as LATP1, LATP2 and LATP3. DSC analysis of LATP2 manufactured specimens (Fig. 5) revealed $16.9 \%$ crystallization of the PEEK matrix. This is a lower \% of cristallinity than the level considered optimal for good mechanical properties ( $35 \%)$ and optimal chemical resistance. In contrast, the crystallinity of representative autoclaved samples was reported as $40 \%$ by Comer et. al. [27]. The decomposition of carbon-PEEK samples starts at temperatures higher than $530{ }^{\circ} \mathrm{C}$ and it is related to exothermic DSC peak (at $\approx 580{ }^{\circ} \mathrm{C}$ ).

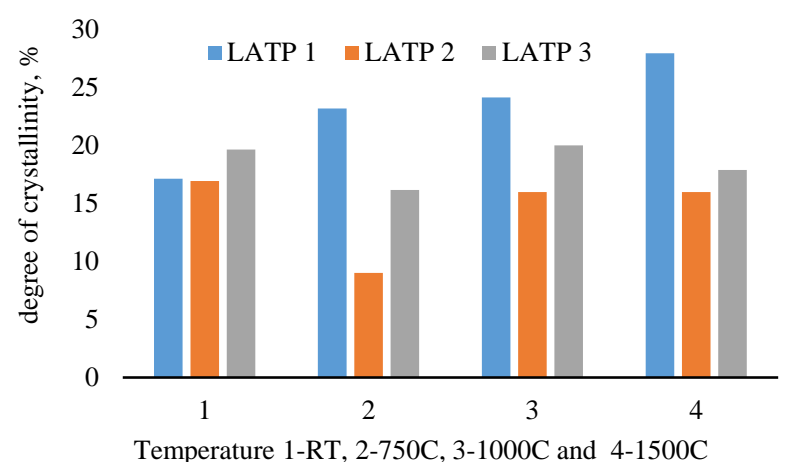

Fig. 7. Degree of crystallinity of laminates LATP1, LATP2 and LATP3 annealed at different temperatures, 1 is room temperature $22^{\circ} \mathrm{C}, 2$ refers to $75^{\circ} \mathrm{C}, 3$ refers to $100^{\circ} \mathrm{C}$ and 4 is $150{ }^{\circ} \mathrm{C}$
There are two possibility for lower crystallinity of LATP 1 and LATP 2 at room temperature (samples are welded tapes before an annealing step):

- First possible reason: during a two-stage pass of the head over the composite material, the bottom side is melted and later during second pass only the top surface is melted. The temperature distribution is not very good through the ply for the very short time of passing the roller over the composite material, namely the heat energy does not reach through the whole thickness of the composite sample.

- The second reason could be that the high cooling rate performed on this sample. The same findings are reported by other authors as well [21].

Fig. 8 presents the degree of crystallinity vs. lamina (UD tape from starting) and laminate (final samples with LATP technology) of composites designated as LATP1, LATP2 and LATP3.

On the other hand, high cooling rates are desirable from the point of view to avoid void rebound once pressure from the roller is released. This study is still in progress; however, the variation and dependence of tool temperature and roller temperature are very important and need to be optimized in further study in order to manufacture compoistes with optimal mechanical properties.

Table 4 shows the crystallinity degree $(X \mathrm{c})$ of PEEK/CF and PPS/CF. According to data presented in Table 4, the Xc of pure PEEK/CF (LATP 2) and pure PPS/CF (LAPT1) can be calculated to $16.94 \%$ and $17.13 \%$, respectively, for studies at room temperature. 
Table 4. Degree of crystallinity $\left(X_{\mathrm{c}}\right)$ of LATP 1 , LATP2 and LATP3 composite materials

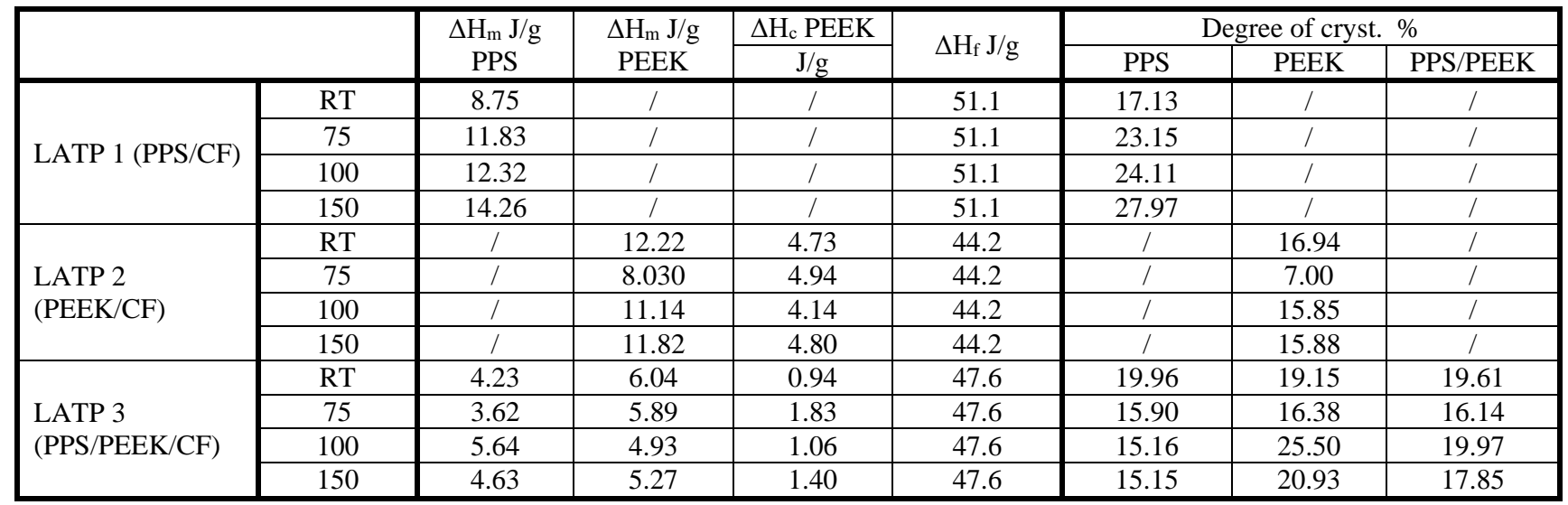

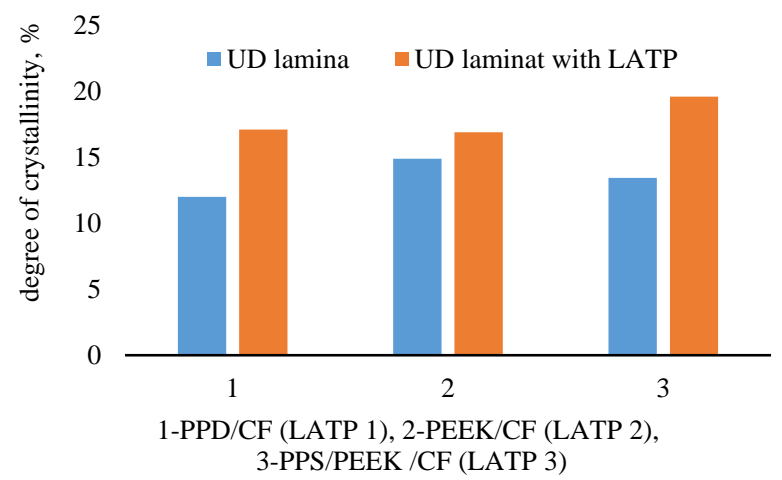

Fig. 8. Degree of crystallinities of laminates LATP 1-3 annealed at different temperatures

From data presented in this study, it could be concluded that LATP 1 sample (PPS/CF) showed an increase in the degree of crystallinity with increasing of annealing temperature from $17.1 \%$ (at room temperature) to $27.9 \%$ (at $150{ }^{\circ} \mathrm{C}$ ). No induced crystallization was observed here before the annealing temperature that shows that the amount of material that could be affected by slow heating has already crystallized during the annealing step.

For results obtained from samples LATP2 and LATP3, the degree of crystallinity is reduced. It was observed that heating the composite material to a certain temperature followed by gradual cooling down in oven, subsequent will cause a small exothermic peak that shows that the amount of material has not already crystallized during the annealing. The induced crystallization probably takes place continuously between the glass transition and the melting temperature for the PEEK matrix which is higher than $150{ }^{\circ} \mathrm{C}$.

Compared to pure PEEK/CF (LATP2), the $X \mathrm{c}$ of PEEK in binary alloys (LATP3) increased when PPS was added. The $X \mathrm{c}$ of PPS in PEEK/PPS alloys decreasesd when PEEK increases for increase of temperature (for LATP 3 presented in Table 4 at room temperature and $150{ }^{\circ} \mathrm{C}$ ). The crystallinity degree of PEEK is improved when PPS/CF was added.

\section{CONCLUSIONS}

This study covers Laser assisted tape placement process of manufacturing of three types of samples based on
LATP1, LATP2 and LATP3 laminates. The work of tested samples LATP 1-3 could be summarized as follows:

1. During the heating step between the glass transition and the melting point, partial melting and recrystallization take place in observed samples which result in a higher degree of perfection in the crystalline regions (LATP1 samples), higher crystallinity.

2. Flexural strength in this study is $\sim 70 \%$ of the flexural strength that is measured with autoclave process. These values are similar with those ones that are already reported in literature (given in Table 3 ). The void \% is higher for the last two samples, that means it affects the flexural strength of the samples.

3. In PEEK matrix samples (LATP2 and LATP3) there is a peak of enthalpy of crystallization at all aging temperatures; the aging occurs at temperatures lower than the glass temperature for the PEEK matrix.

4. Since the glass transition temperatures of thermoplastic matrices are: $\sim 155^{\circ} \mathrm{C}$ for PEEK and $85{ }^{\circ} \mathrm{C}$ for PPS, it is already in author's plan to continue the aging of these composites at higher temperatures and consequently examination of the degree of crystallinity of those annealed composite laminates.

5. Void contents are within the allowed void tolerance for thermoplastic such as for LATP1; however, in further studies targets are focused to manufacture of composite materials by ATP with-less voids contents and better consolidated laminates.

\section{Acknowledgments}

The authors would like to acknowledge the support of the research team from Institute for advanced composites and robotics- Prilep and engineering team from Mikrosam A.D. -Prilep (R.Macedonia).

\section{REFERENCES}

1. Dubé, M. Static and Fatigue Behaviour of Thermoplastic Composite Laminates Joined by Resistance Welding, PHD Thesis, McGill University Montreal, Canada, 2007: pp. 63-94.

2. Brecher, C., Emonts, M., Schares, R.L., Stimpfl, J. $\mathrm{CO}_{2-}$ Laser-assisted Processing of Glass Fiber-reinforced Thermoplastic Composites Proceedings of SPIE 8603, 2013: pp. $86030 \mathrm{H}$. https://doi:10.1117/12.1000243. 
3. Fink, B.K., Gillespie, J.W., Ersoy, N.B. Thermal Degradation Effects on Consolidation and Bonding in the Thermoplastic Fiber-Placement Process, Army research laboratory, 2000: pp. 10-29.

4. Maurer, D., Mitschang, P. Laser-powered Tape Placement Process - simulation and Optimization Journal Polymer \& Composites Science 1 (3) 2015: pp. 129-137. https:// doi: 10.1080/20550340. 1114798

5. Reichardt, J., Baran, I., Akkerman, R. New Analytical and Numerical Optical Model for the Laser Assisted Tape Winding Process Composites Part A 107 2018: pp. $647-656$.

https://doi.org/10.1016/j.compositesa.2018.01.029

6. Bandaru, A.K., $\quad$ Clancy, G., $\quad$ Peters, D., Ronan O' Higgins, R., Weaver, P.M. Interface Characterization of Thermoplastic Skin- Stiffener Composite Manufactured using Laser-Assisted Tape Placement AIAA/ASCE/AHS/ASC Structures, Structural Dynamics and Materials Conference 2018

https://doi.org/10.2514/6.2018-0481

7. Clancy, G.J., Peeters, D., Oliveri, V., Jones, D., O'Higgins, R., Weaver, P.M., Steering of Carbon Fiber/Thermoplastic Pre-preg Tapes using Laser-Assisted Tape Placement AIAA/ASCE/AHS/ASC Structures, Structural Dynamics, and Materials Conference 8-12 Jan. Kissimmee, Florida 2018 https://doi.org/10.2514/6.2018-0478

8. Clancy, G., Peeters, D., Oliveri, V., Jones, D, O'Higgins, R.M., Weaver, P.M. A Study of the Influence of Processing Parameters on Steering of Carbon Fibre/PEEK Tapes using Laser-Assisted Tape Placement Composites Part B 2018: pp. 243-251. https://doi.org/10.1016/ j. compositesb.2018.11.033.

9. Di Francesco, M., Giddings, P.F., Scott, M., Goodman, E., Dell' Anno, G., Potter, K. Influence of Laser Power Density on the Meso Structure of Thermoplastic Composite Preforms Manufactured by Automated Fibre Placement In International SAMPE Technical Conference Journal of Advanced Materials (3) 2016: pp. 141-155.

10. Stokes-Griffin, C.M., Compston, P., Matuszyk, T.I., Cardew-Hall, M.J. Thermal Modelling of the Laser-assisted Thermoplastic Tape Placement Process Journal of Thermoplastic Composite Materials $28(10)$ 2013: pp. $1445-1462$.

https://doi.org/10.1177/0892705713513285

11. Stokes-Griffin, C.M., Compston, P., Laser-Assisted Tape Placement of Thermoplastic Composites: The Effect of Process Parameters on Bond Strength Sustainable Automotive Technologies 2014: pp. 133-141. https://doi.org/10.1007/978-3-319-01884-3_13

12. Cornelis, H., Kander, R.G., Martin, J.P. Solvent-induced Crystallization of Amorphous Poly (ether ether ketone) by Acetone Polymer 37 (20) 1996: pp. 4573-4578. https://doi.org/10.1016/0032-3861(96)00246-7

13. Blundell, D.J., Osborn, B.N. The Morphology of Poly (Aryl-Ether-Ether- Ketone) Polymer 24 (8) 1983: pp. 953-958.

https://doi.org/10.1016/0032-3861(83)90144-1

14. Muzzy, J.D., Bright, D.G., Hoyos, G.H. Solidification of Poly (Ethylene Terephthalate) with Incomplete CrystaIlization Polymer Engineering and Science 18 (6) 1978: pp. $437-442$. https://doi.org/10.1002/pen.760180604

15. Unger, W.J., Hanse, J.S. The Effect of Thermal Processing on Residual Strain Development in Unidirectional Graphite
Fibre Reinforced PEEK Journal of Composite Materials 27 (1) 1993: pp. 59-82. https:// doi: 0021-9983/93/01 0059-24.

16. Tierney, J.J., Gillespie, Jr.J.W. Crystallization Kinetics Behavior of PEEK Based Composites Exposed to High Heating and Cooling Rates Composites Part A 35 (5) 2004: pp. $547-558$. https:// doi: 10.1016/j.compositesa.2003.12.004.

17. Risteska, S., Samak, S., Sokoloski, Z., Bogdanoski, D. Integrated Production Solutions for Thermoplastic Materials 6-th International Scientific Conference Space Technologies 2017: pp. 158.

18. Risteska, S., Samak, S., Sokoloski, Z., Bogdanoski, D. Solutions for Production and Properties of Thermoplastic Composites The $10^{\text {th }}$ Asian-Australasian Conference 16-19 October, 2016: M28-2.

19. Hoang, M.D. Procedure for Making Flat Thermoplastic Composite Plates by Automated Fiber Placement and Their Mechanical Properties, MSs Thesis Concordia University Montreal, Quebec, Canada, 2015.

20. Talbott, M.F., Springer, G.S., Berglund, L.A. The Effects of Crystallinity on the Mechanical Properties of PEEK Polymer and Graphite Fiber Reinforced PEEK Journal of Composite Materials 21 (11) 1987: pp. 1056-1087. https://doi.org/10.1177/002199838702101104

21. Sonmez, F.Z., Hahn, H.T. Modeling of Heat Transfer and Crystallization in Thermoplastic Composite Tape Placement Process Journal of Thermoplastic Composite Materials 10 (3) 1997: pp. 198-240. https://doi.org/10.1177/089270579701000301.

22. Xu, H., Hu, J. Study of Polymer Matrix Degradation Behavior in CFRP Short Pulsed Laser Processing Polymers (8) 2016: pp. 299-313. https://doi.org/10.3390/polym8080299.

23. Comer, A., Hhammond, P., Ray, D., Lyons, J., Obande, W., Jones, D., O'Higgins, R., McCarthy, M. Wedge Peel Interlaminar Toughness of Carbon-fibre/peek Thermoplastic Laminates Manufactured by Laser-assisted Automated-Tape-Placement (LATP) Conference: SETEC 2014 Tampere Conference\&Table Top Exhibition 2014: pp. $51-119$. https:// doi: 10.13140/2.1.1305.9847.

24. Kuo, M.C., Tsai, C.M., Huang, J.C., Chen, M. PEEK Composites Reinforced by Nano-sized $\mathrm{SiO}_{2}$ and $\mathrm{Al}_{2} \mathrm{O}_{3}$ Particulates Materials Chemistry and Physics 90 2005: pp. $185-195$.

https://doi:10.1016/j.matchemphys. 2004.10.009

25. Spruiell, J.E., Janke, C.J. A Review of the Measurement and Development of Crystallinity and its Relation to Properties in Neat Poly (Phenylene Sulfide) and its Fber Reinforced Composites, Technical Report, Oak Ridge National Laboratory, 2004.

26. Herrod-Taylor, A. The Crystallization of Poly (Aryl Ether Ether Ketone) (PEEK) and its Carbon Fibre Composites, $M S c$ Thesis, University of Birmingham, United Kingdom, 2011.

27. Comer, A.J., Ray, D., Obande, W.O., Jones, D., Lyons, J., Rosca, I., O’Higgins, R.M., McCarthy, M.A. Mechanical Characterization of Carbon Fibre-PEEK Manufactured by Laser-assisted Automated-Tape-Placement and Autoclave Composites (Applied Science and Manufacturing): Part A 69 2015: pp. $10-20$. https://doi.org/10.1016/j.compositesa.2014.10.003

28. Gao, S.L., Kim, J.K. Cooling Rate Influences in Carbon Fbre/PEEK Composites Composites Part A: Applied Science and Manufacturing 31 (6) 2000: pp. 517-530. 
https://doi.org/10.1016/S1359-835X(00)00009-9

29. Grouve, W. Weld Strength of Laser-assisted Tape-Placed Thermoplastic Composites, $P h D$ Thesis, University of Twente, Enschede, The Netherlands, 2012.

30. Cai, X. Determination of Process Parameters for the Manufacturing of Thermoplastic Composite Cones Using Automated Fiber Placement, MSc Thesis, Concordia University Montreal, Quebec, Canada, 2012.

31. De Jesus Silva, A.J., Berry, N.G., da Costa, M.F. Structural and Thermo-mechanical Evaluation of Two Engineering Thermoplastic Polymers in Contact with Ethanol Fuel from Sugarcane Materials Research 19(1) 2016: pp. 84-97. https://doi.org/10.1590/1980-5373-MR-2015-0480.

32. Kilroy, J.P., Ó‘Brádaigh, C., Semprimoschnig, C.O. Mechanical and Physical Evaluation of a New Carbon Fbre/PEEK Composite System for Space Applications SAMPE Journal 44 (3) 2008: pp. 22-34.

33. Lamontia, M.A., Gruber, M.B., Tierney, J.J., Gillespie, Jr.J.W., Jensen, B.J., Cano, R.J. Modelling the Accudyne Thermoplastic in Situ ATP process In: Proceedings of SAMPE conference 23-24 March, 2009.

34. Cano, R.J., Belvin, H.L., Hulcher, A.B., Grenoble, R.W. Studies on Automated Manufacturing of High-Performance Composites Presented at the American Helicopter Society Hampton Roads Chapter, Structure Specialists' Meeting, Williamsburg, Virginia, USA, October 30-1 November 2001.
35. http://welshcomposites.co.uk/downloads/Microscopy\%20W ebinar.pdf

36. Hayes, B.S., Gammon, L.M. Optical Microscopy of FiberReinforced Composites - Chapter 1: Introduction Composite Materials and Optical Microscopy, ASM International, Materials Park, Ohio 44073-0002, 2010. www.asminternational.org

37. Paciornik, S., D'Almeida, J.R.M. Measurement of Void Content and Distribution in Composite Materials through Digital Microscopy Journal of Composite Materials 43 (2) 2009: pp $101-112$. https://doi.org/10.1177/0021998308098234

38. Image $\mathbf{J}$ program developed at the National Institutes of Health (NIH) https://en.wikipedia.org/wiki/ImageJ

39. ASTM D 3171. Standard Test Methods for Constituent Content of Composite Materials.

40. ASTM D 792. Standard Test Methods for Density and Specific Gravity (Relative Density) of Plastics by Displacement.

41. EN ISO14125. Fibre-reinforced Plastic Composites Determination of Flexural Properties English version of DIN EN ISO 14125 (ISO 14125: 1998).

42. Samak, S., Sokoloski, Z., Risteska, S., Bogdanoski, D. Improving the Final Properties of Thermoplastic Composites Manufactured with Laser Automated Tape Placement (LATP) The $13^{\text {th }}$ SAMPE CHINA Conference \& Exhibition 16-18 May, 2018. 